April - 2003

\title{
Adults Contemplating University Study at a Distance: Issues, themes and concerns
}

\author{
Jenny Bird and Chris Morgan \\ Southern Cross University \\ Australia
}

\begin{abstract}
This study identifies and explores a range of themes, issues and questions that commonly confront adults contemplating enrolment in university, and why they persist. The study focuses particularly on issues facing prospective adult distance education learners. From a range of interviews, six themes were identified including fears, motivation, support from home, academic preparedness, suitability of programs, and identity change.

It is argued that the more effective we become at information provision, guidance and preparation of adult pre-entry open and distance learners, the more likely students will experience a smooth transition to study, thus improving both student satisfaction and retention rates. Successful intervention with prospective distance education learners at this early point should aim to assist the process of informed decision making, which could result equally in an individual deciding not to pursue university study. The findings in this study should be particularly useful for those academics, course advisors, student counsellors, teachers in preparatory programs, and university information and support officers, and others who provide adult distance students, with preenrolment information and advice.
\end{abstract}

\section{Background}

With the continued expansion of open, distance and flexible learning, opportunities for matureaged students to pursue higher education continue to rise. In Australia approximately only half of those students entering university have come directly from high school, and mature aged entry has consistently been the largest sector of growth in many universities. A substantial proportion of adult distance education students are women who often enter higher education after long absences from any formal education and balance a variety of complex commitments in their lives. What prompts them to create such upheaval in their lives, and those of their families, when they already inhabit such busy worlds? What do we know of their needs during the decision-making process of returning to study? Do they have access to appropriate guidance or counselling? Do they have reasonable expectations about what a university education at a distance may offer? Do they understand what will be expected of them as distance learners? Have they any appreciation of how study will affect their lives and families?

To obtain information on issues and concerns of adults considering entry to higher education at a distance, it is the literature of student attrition that is most helpful. In a sense, this is unfortunate 
Bird \& Morgan Adults Contemplating University Study at a Distance: Issues, themes and concerns

in that it suggests we must wait until a student drops out before exploring their needs. In open and distance education, a number of studies have explored reasons for student discontinuance (e.g., Garland, 1993; Brown, 1996; Parr et al., 1996; Grace and Smith, 2001) and which also speak to the kinds of interventions that open and distance educators may apply to be more proactive in supporting learners. There seems to be wide agreement that success of adults enrolled in distance education is influenced by the interplay of a variety of factors. Some of the more commonly cited issues in discontinuance include:

- Conflicting work and family commitments: As most adult distance learners study part-time and need to balance a range of responsibilities, conflicting commitments is a frequently cited problem. In many instances, study will necessarily assume a lower priority than family and work commitments, particularly when unforeseen events intervene (Thorpe, 1987; Evans, 1994).

- Financial strain: Full or significant part-time study will often necessitate acceptance of reduced income, combined with the additional burden of course fees and expenses. For single parent families and lower income workers, this may not be sustainable over long periods of time.

- Predisposition and readiness for independent learning: The solo study arrangements that distance education most commonly affords are clearly not suited to everyone. Students are often required to find far greater reserves of selfdiscipline and time management skills than in prior educational experiences (Calder and McCollum, 1998; Candy, 1991).

- Availability and timeliness of appropriate learning support: Learning support is usually offered in a variety of forms, including preparatory programs and semester-based support. Yet the level of learning support available to distance students is highly variable and often non-existent. Students are commonly left to develop academic skills such as essay writing by trial-and-error. Those who fail to develop them quickly enough may become dispirited, perhaps confirming their suspicions that they do not have the ability to succeed (Morgan et al., 1998).

- Accessibility and user-friendliness of administrative systems and staff: Admissions and enrolment centres usually provide a first point of contact for many prospective students. The accuracy and timeliness of information provided to students is critical to their future. Evans (1994) describes the difficulty that adults studying at a distance experience when seeking advice from educational institutions. Prospective students are often unfamiliar with the culture of higher education and how to formulate the right questions.

- Ease of contact and approachability of academic staff: For external students, establishing satisfactory contact with academic staff is one of the major afflictions of life as an external student. Distance learners typically must study at night and on weekends when academic staff tend not to be available. Inability to obtain timely, practical input or feedback may be dispiriting and is a commonly cited reason for discontinuance (e.g., Parr et al., 1996; Brown, 1996).

- Suitability of program content or its design and delivery methods: Inevitably many students will discover that their selected program of study does not meet their needs, career goals, or leaning preferences. However, questions arise 
Bird \& Morgan Adults Contemplating University Study at a Distance: Issues, themes and concerns

regarding how adequately the program is described and promoted to prospective students in terms of detailed information on curricula, workload, career opportunities, and academic expectations.

- Ability to comprehend and deal with assessment requirements: Assessment is the engine that drives learning; it is also a focal point around which students' concerns and fears coalesce. For adult students with fears regarding their abilities to succeed, assessment tasks become major 'hot spots' in their progress. Assessment schemes that fail to communicate a rationale or clear expectations, or fail to give adequate feedback, or require students to undertake tasks that have little personal meaning or relevance, may provoke considerable anxiety and discourage students. Rather than being a tool to build skills and confidence, assessment may become a means of confirming feelings of inadequacy (Morgan and O’Reilly, 1999).

- Level of motivation and commitment to study: Individual student motivation and commitment are not static. Over the span of a three to five year program of study, distance learners' motivations may change enormously, due to the nature of their incremental achievements, shifting perspectives, and family and financial circumstances. For some, once the initial curiosity and desire to prove something to themselves is extinguished, they may need to seek out more practical or tangible outcomes, such as improved career prospects, in order to persevere to completion (Thorpe, 1987).

- Access to and confidence with computers and other necessary technology: Adults entering university without pre-requisite information technology skills are at considerable disadvantage initially, which may compound their sense of being overwhelmed or not 'belonging.' Their ability to overcome these initial hurdles will be closely related to the level of understanding and practical support offered by the university.

- Language, literacy or learning disability issues: It is accepted that many students gaining entry to higher education will have a learning disability or a first language other than English. Such students face particular and ongoing hurdles that will often leave them vulnerable and prone to discontinuance through the sheer weight of their struggles. The level of support available to students, both within and outside the university, will be a critical factor in their success.

- Impact of previous educational encounters: Expectations of students entering university may be largely formed by previous educational experiences and study approaches. Negative prior experiences will affect students' confidence and selfconcept, as well their ability to form new teaching and learning relationships, and develop more appropriate approaches to study. For some, a lifetime of responses to highly teacher controlled, teacher-centered education may be difficult to cast off, in favour of independent and lifelong learning strategies.

- Problems regarding isolation and not 'belonging' in an academic community: The potential for isolation in distance learning is a well-documented phenomenon, and may be both a geographical and psychological construct. The ability of today's distance learner to become part of a learning community depends on one's technological proficiency and ability to engage in certain kinds 
Bird \& Morgan Adults Contemplating University Study at a Distance: Issues, themes and concerns

of academic and social discourse offered through online learning. Some older adult learners, whether they study on campus or at a distance, may encounter the generational problem of insufficient peer support and simply 'not belonging' in a younger person's world.

- Support from partners: One's success as a distance learner is often predicated on the support of a partner who is prepared to take a greater share of domestic and/ or financial responsibility during the often long period of study. Evidence suggests that support is more likely to be forthcoming to males within the partnership than to females, which highlights the particular plight of women returning to study while maintaining a heavy domestic burden (Evans, 1994).

When viewing this list, one cannot help but wonder whether many of these issues could have been anticipated by students through provision of timely and appropriate information and guidance counselling during the pre-enrolment time. Of course, study plans may change radically through, say, the illness of a child, the sudden loss of work, or a change in career directions. Yet there are other significant issues in discontinuance, such as a student's predisposition, motivation, level of literacy, past learning experience, and ambitions for the future which are less temporal and for which the implications for study might be anticipated. The difficulty for most prospective distance education students is to anticipate and articulate these issues at pre-enrolment time, in order to be prepared for entry.

\section{Methodology}

\section{Overall Approach}

The overall research approach taken in this study was phenomenological. The research question focused on the range of themes, issues, and questions that commonly confront adults contemplating enrolment in university, with particular attention given to issues experienced by for distance education students. The phenomenographic method is useful for "mapping the qualitatively different ways in which people experience, conceptualise, perceive, and understand various aspects of phenomena in the world around them” (Marton, 1986, p. 31). As such, phenomenological research concerns itself with the phenomena under study as they are understood and construed by the participants, rather than an attempt to describe the phenomena as they are.

\section{Sample}

A first round purposive sample of 20 mature aged university students was chosen for the study. Although the sample included both on-campus and distance education students, there was a strong focus on the sometimes overlooked issues facing distance learners. The sample was chosen with the aim of meeting both requirements identified by Polkinghorne (1991, p. 11) for an adequate database - "intense descriptions of the phenomenon under investigation and enough variation in the data to develop a comprehensive structural description." The sample was therefore chosen for maximum variation across a wide range of variables:

- $\quad$ Age - participants age ranged from 21 to 56

\section{- Gender}


Bird \& Morgan Adults Contemplating University Study at a Distance: Issues, themes and concerns

- Ethnicity - one participant had recently migrated to Australia and spoke English as a second language. One indigenous Australian student agreed to be involved in the study, but withdrew due to family reasons

- Disciplinary area - participants had enrolled in a cross section of undergraduate programs available at Southern Cross University

- Flexible enrolment pattern - participants reflected a wide range of enrolment patterns: fully internal, fully external, flexible combinations of both, part time students, fulltime students, combinations of both

- Attrition/ retention - some participants were currently enrolled in undergraduate programs, some had completed degrees, one had left, one had withdrawn from one program left and subsequently re enrolled in another

- Articulateness - all participants were chosen on recommendations of their ability to 'tell their story'

- $\quad$ Special needs - one participant was severely dyslexic

- Family commitments - participants were either single, married with children, married without children, single parents, or divorced with adult families

- Work commitments - some participants worked part time, others worked fulltime, and others were not in employment

- Financial status - some participants were financially independent, others were on a government-funded programme, Austudy, and supplemented by student loans, some were financially dependent on spouses or partners

All participants had enrolled in university at some time: some were currently studying, some had left prior to completion, and some had gone on to complete further degrees.

The second round of sampling occurred after the first group interviews. This sample consisted of seven people. Whilst this second group was also chosen for maximum variation on the variables described above, an additional factor was the degree to which participants could reflect upon and articulate the details of the decision making process which led them to enrol in university and the relationship between this process, type of preparation they undertook, type of support they sought, and their subsequent success or otherwise at university.

\section{Data Collection and Analysis}

\section{First Round of Interviews}

Participants were invited to attend one of two group interviews, each three hours in duration. The sessions were informal and conducted in a relaxed and friendly setting with wine and food. All sessions were filmed and recorded with a fixed position digital video camera and sound recording equipment placed in an unobtrusive place in the room. It was anticipated that this informal narrative approach would engender rich, in-depth, reflective data of participants' experiences in deciding to attend university. Questions and comments made by the researchers were informed by 
Bird \& Morgan Adults Contemplating University Study at a Distance: Issues, themes and concerns

both tacit knowledge of what the issues are for mature aged students generally, and more specifically, a framework of issues developed by Evans (1994). Two researchers and one audiovisual technician were present at all times during the interviews. The researchers are both educational designers with long histories working in open and distance education, and with mature aged students. All efforts were made by the researchers to build trust between themselves and each participant on an individual level, and within the participant group as a whole.

Interviewers asked one open-ended question of each participant: "Can you tell us the story of how you came to decide to attend university?” Each participant then proceeded to tell their own story to the researchers, without interruption. Dialogue between participants occurred naturally at the completion of each story. Non-directive interviewing such as this is common in phenomenological research, with each interview/ narrative taking a different path. According to Inglis (1996, p. 271): "This non-directive interview technique therefore relies on the researcher having a detailed knowledge of the specific subject matter which forms the focus of the investigation so as to be able to generate questions which adequately probe subjects' understanding while the interview is in progress.”

Researchers engaged in a process of data analysis common to phenomenographic research and described by Lincoln and Guba (1985), Glaser and Strauss (1967) and Marton, Hounsell and Entwhistle (1997). The two researchers viewed the videotaped group interviews, took notes, and broke each participant's story into units. The units contained both of Lincoln and Guber's (1985) characteristics - they were 'heuristic,' in that they added to an understanding of the issue, and they were 'stand alone' in that each unit was a discrete part of the participant's overall story. Using a process of 'constant comparison,' each unit was compared to a previous unit, enabling the researchers to develop a set of categories into which all the units loosely fit. The final category sets, and the categories themselves, were then reviewed both for overlap and relationship. As the list of categories stabilised and reduced, each category became saturated with data, and the scope of the theoretical boundaries of the study began to emerge. Some categories were eliminated, some merged, and others were identified as needing more data.

This process of analysis allows for what Marton et al., (1997) describe as a three stage process of abstraction whereby the focus of analysis moves from the content of the individual interviews to a 'pool of meanings' (p. 42) divorced from the interviews and delimited by the categories, to the establishment of a hierarchy of similarities and differences. From this process, categories emerged which were representative of all interviewees' experiences, whether they be on-campus or distance learners, whilst others were unique to on-campus and distance learners respectively.

\section{Second Round of Interviews}

A further purposive sample of six participants was chosen for a second phase of data collection. Participants were chosen because their stories suggested to the researchers the potential for further rich data in some categories, and for their ability to articulate their stories. Interviews were conducted with individual participants by both researchers. Interviews were much more structured and directed by the interviewer, with questions designed to probe deeper into aspects of the participant's story that required more data. Interviews were also useful in checking the researchers' understandings from the first round of data analysis. Questions such as the following were posed to participants: "We would like to revisit the part of your story where you told us about your fears of being too old to fit in to a young person's culture. Can you tell us some more about that?" 
Bird \& Morgan Adults Contemplating University Study at a Distance: Issues, themes and concerns

\section{Results}

Six themes were identified in this study. Each theme is described and illustrated with a selection of excerpts from the participant interviews. All themes were not necessarily articulated by every participant, so should not be viewed as representative. They did, however, emerge from the data analysis of both rounds of interviews as dominant themes. As Marton et al., (1997) points out that it is difficult to fully represent such data collected in research. Not all data (i.e., quotations) can be included. What has been included is a selection of typical comments from the full body of data within each category/ theme. Pseudonyms have been used to protect the identities of the participants.

\section{Theme 1: Fears}

All respondents in this study expressed a range of fears and doubts about studying at university, irrespective of their status as on-campus or distance learners. In fact, for prospective students at this early stage of enquiry, fears and doubts loom large, unfettered by any experience with the realities of contemporary Australian universities, and fed by deeply held negative beliefs about their ability to achieve in an educational environment. Participants approached university studies with a sense of awe, and with a set of expectations against which they had already, to some degree, judged themselves inadequate. Respondents identified the objectives of overcoming these fears and building confidence as key to their success.

Some respondents carried expectations and images of university as a place for an elite intelligentsia, to which they perceived they did not belong.

Kym: "When I first came, I felt quite intimidated. I thought that everyone was going to be highly intelligent and that I was going to be like a duck out of water. I didn't know what sort of conversation I'd be able to have with people there, and I thought there was going to be all these demi-gods running around with degrees and doctorates and things like that and that I would somehow be inferior.

"Then the next big fear I had was 'well how do I deal with this, how do I study, how do I prepare papers, am I being productive with what I'm doing or was I having myself on?' And over a couple of weeks I found that I could deal with the work, not easily at first, but then it came easily, once I got my confidence."

One respondent, the first in her family to ever attend university, came from an isolated rural background; her story highlighted just how removed her experience had been from university life:

Judy: "I was conscious of the fact that I came from a background that was not academic. I'm really lucky that I have my husband's family who realise what university life is about, which is excellent."

Others imagined universities as places for young people, places where mature aged people would be too old and would not be accepted:

Phyllis: "The major concern I had was that I was coming into a young person's world. Even though I was connected with my children, I was coming into a young person's society and you worry that you won't be accepted." 
Others recalled negative experiences at school and the establishment of a set of negative beliefs about their abilities and intelligence:

Brett: "Pretty soon I learned that if the teachers think you're dumb, if the other students think you're dumb, if you're no good at sport, you were hammered by the kids at school and the teachers didn't give you the time of day. So I was put in all the dumb classes and by the time I got to 14, I had such a negative belief cycle."

Interestingly, respondents in this study suggest that it is a student's motivation, not their fears, which will predicate success at university. Whilst acknowledging fears and doubts as a significant theme in their journey, both on-campus and distance education respondents advised that once they faced their fears, their confidence and skills grew. It seems that prospective students who have little or no real experience or contact with university, project their fears and doubts into this vacuum. When they have had prior negative experiences with educational institutions, such students are particularly vulnerable. Whilst the fears experienced by prospective on-campus and distance learners may be similar, the opportunities to diminish those fears through benchmarking, socialising, and weekly contact with academic staff cannot be assumed or looked forward to by prospective distance students with the same certainty as prospective students who choose to study on-campus. Prospective distance students face an uncertain and varied future in this regard, with differing degrees of support available to them.

Prospective distance education students need to be apprised of the potential for fears to grow out of proportion in the isolated learning space in which they may find themselves. Common fears need to be heard, affirmed, and normalised. Detailed explanations of the types of academic and student support provided by the particular university need to be provided so that prospective distance students can feel confident that support is not only close at hand, but that it is also something to which they are entitled.

\section{Theme 2: Motivation to Succeed}

Most participants in this study saw returning to university as a life changing event, and something that was going to cause considerable upheaval to their existing circumstances. This upheaval was typified by Phyllis's comment:

Phyllis: "All of a sudden you are doing things to yourself that you just think 'Oh my goodness, why oh why? I could go home and live quite happily. I don't need this."”

The question of 'Why do it to myself?' had a variety of responses, reflecting the diversity of mature-aged students' lives and interests:

Sharon: "I'd been thinking about it for a long time to do some kind of course and Jackson my youngest had just gone to pre-school for two days a week and I felt that it was time then to start doing something for myself."

Frank: "I recognized the need for advancement, promotion with the service. I needed to improve my communication skills and be more aware of the public need." 
Bird \& Morgan Adults Contemplating University Study at a Distance: Issues, themes and concerns

Phyllis: "I was married for 25 years and my husband and I agreed to separate and I guess after that time I was looking to reconnect myself with the world. My daughter was very keen for me to go back to nursing. I really felt that nursing had moved along so much that it would be impossible for me to just walk back into it."

In these comments we find a variety of motivations and educational orientations including vocational, academic, and personal, each with its own accompanying interests, aims, and concerns. Gibbs, Morgan and Taylor (1984) distinguish between those individuals who are intrinsically motivated (the inherent value to the person) or extrinsically motivated (external validation or recognition). For those involved in the support and counselling of prospective distance students, these may be useful indicators or predictors of potential issues and needs. For example, 'doing something for myself' or 'reconnecting with the world' may be valid reasons for considering tertiary study, but will it be sufficient to sustain one over a whole program? What other motivations and stimuli are needed to sustain one through many years of part-time study? Motivation, of course, is not static and may vary considerably during a program of study. Moreover, one's motivation may never fall neatly into one or another category, but may be a combination of a variety of interests and needs, including new social opportunities, satisfaction of continued academic success, public recognition of achievements, enhanced career prospects, new recreational outlets, new ways of thinking and seeing the world, and so forth.

With the benefit of hindsight, discontinued students may often reflect on the inadequacy of their original motivations. For example:

Kym: "I was talked into coming to university by a boyfriend who thought that it was extremely important to have a degree in something. It wasn't relevant whether you were interested in that something, or whether you enjoyed that something, as long as you had a degree."

It is unlikely that Kym would have explained her motivation this way upon entering university. Yet with some robust pre-enrolment guidance, she may have spared herself the ordeal of a 'boring' and fruitless encounter, and thus avoid becoming another attrition statistic.

The challenge for prospective distance education students is to be sufficiently self-reflective regarding their own needs and to seek guidance - or reality check - as to whether those needs can be realistically met and how they may evolve over time within an academic community. Many prospective distance learners will be considering part time study and will be looking at studying over extended periods of time. Sustaining motivation over what might be a six or eight year period poses particular challenges which need to be discussed, as do the challenges to motivation that ever changing demands of work, family and financial commitments may bring. The degrees of flexibility offered by particular programs, and time limits on completion, need to be weighed against the risks of losing motivation over sustained periods of time.

\section{Theme 3: Support from Home}

One of the more difficult issues for prospective distance education students and their families is to envisage the impact of study will have upon family life. Recognizing the additional financial burden and decreased availability for family life due to study commitments, most adult learners need the support of their partners or loved ones. Although partners may be supportive in principle, the full impact of this transition has yet to be understood or experienced. Experiences 
such as those of Frank are a good example of the kind of sacrifice that is often made by supporting partners:

Frank: "Being a married man, three kids, all at school, a wife that's working, studying for a degree is an extremely selfish act. You're denying, although you don't see it at the time, your access or availability to your kids, to your wife. You're doing your study, and the wife's keeping the kids quiet, she's out in the garden so you can study. It's not my degree; it's our degree."

In open and distance education, men are more likely to be involved in study as part of their employment or career path and are sometimes provided with support from their employers to be able to complete their study (Evans, 1994). Often, men's study goals are seen as more legitimate or of greater priority regarding the long-term financial security of the family. Whilst these comments, to some degree, are stereotypical of traditional family arrangements, it is nevertheless important to acknowledge the often quite markedly different experiences of men and women returning to study. Contrast Frank’s experience with that of Judy:

Judy: “I've got really good kids and a supportive husband, but they're also wanting my love and my time and wondering why I'm sitting with my head buried in books in the afternoon and then in the evening. It was hard for me to find a measure because I wanted to do my uni thing which was new and important to me, the kids wanted me and Peter wanted me and I still had to go to work and keep the income as well. So the first six months was a bit ordinary. We all thought: 'This is awful!' I can remember coming home one night and saying to Peter, my husband, 'I must be really stupid. How can anybody do this?' "

In his study of distance learners, Evans (1994, p 64) found that there is still considerable inequality in the support offered by partners, relative to one's gender. "It is much more usual" he argues, "to find men learners who assume their partner's support and then take it for granted throughout their courses. In contrast, women do not take it for granted; they are often extremely grateful, even though for the most part, these supportive men are often doing little more than could reasonably be expected in a fair, egalitarian world."

Judy's dilemma was founded on her inability to do everything to her normal exacting standards, while her family maintained largely unaltered expectations regarding her domestic role. Judy certainly is not 'stupid' as she asserts, but was experiencing a painful lesson regarding the necessity to prioritise her commitments, lower some expectations of herself, and negotiate more fruitfully with her family to achieve the necessary space she required in these difficult early stages of her study. It highlights Evans' (1994) concern regarding the fragility of women learners who are unfamiliar with giving higher priority to their own needs. Judy and her family made a successful transition and embraced her university commitments. However, not all women are so fortunate. Evans (1994, p. 63) says: "It is hard to underestimate the immense difficulties some women will face with their partners.”

For any part-time distance learner with work and family responsibilities, there are clearly significant changes required of the family routine. Failure to anticipate at least some of these changes, and most importantly to involve the family and gain informed support for this transition, may create family discord and impair one's ability to proceed with study. These issues need to be canvassed thoroughly with prospective distance education students, particularly women, so that the process of negotiation with family members can occur prior to commencing study. However, 
Bird \& Morgan Adults Contemplating University Study at a Distance: Issues, themes and concerns

prospective students also need to know what assistance they can access if they find themselves, like Judy, under considerable stress in the first six months of study.

\section{Theme 4: Academic Preparedness}

Mature aged students enter university through a myriad of entry schemes, many without the necessary level of educational qualifications demanded of school leavers. Many mature aged students enter university after long periods away from study without the requisite skills to ensure their success. Not all participants in this study took initiatives to prepare for returning to university. Of those who did, all spoke of the value of seeking out and engaging in a variety of preparatory activities prior to commencing study, and of the value of consulting and seeking out information about their programs of study. Each of the following students accessed on-campus preparatory courses, irrespective of their enrolment status:

Judy: "I think preparatory courses are really important to know what you're in for because your first essays at university are a really big deal and if you've had some experience of what to expect, that's going to make it easy for you."

Sharon: "They [preparatory courses] gave me the confidence to know that I could do it and also enabled me to gain skills towards my degree.”

Brett: "I went and did the tertiary preparation certificate at TAFE for one year and that was a real learning curve for me ... It basically separated my spelling from my intelligence." [This participant was diagnosed with severe dyslexia during his first year at university.]

Frank's story, however, is a good example of what often happens to distance education students in relation to student support. Frank was a distance student who completed six units of study, and was in the second year of his degree, before he was 'picked up' by a lecturer who recommended that he complete an academic skills development program designed specifically for distance students. Frank was unaware of this resource, and despite his obvious need for academic skills development, had not been referred to it until well into his studies. In fact, Frank might be considered lucky that he was picked up at all:

Frank: "I was just finishing second year and one of the lecturers said 'I'm going to give you a pass on the proviso that you go to the Learning Assistance Centre and do a course next year called Success in Tertiary Education.' He said, 'It will teach you how to write, research, investigate.' I enrolled and the veil lifted."

Most Australian universities offer enabling programs and other preparatory courses on campus for students seeking enrolment. Less common are print or flexibly delivered, enabling or preparatory courses to distance students. Distance education students are less likely to attend on campus Open Days and Orientation Days where preparatory courses are advertised. Print based promotional material for preparatory courses may arrive embedded in copious amounts of other material, overwhelming a new student, and thus often left unread.

Prospective distance education students need encouragement to explore preparation courses that are available in their local area, as well as those offered by the university in which they are interested. Whilst it may appear unattractive to extend the period of study by an extra six to 
Bird \& Morgan Adults Contemplating University Study at a Distance: Issues, themes and concerns

twelve months, the results of this study suggest that the investment in preparation will be well worth it.

\section{Theme 5: Suitability of Programs}

Often the most difficult and confusing task confronting any prospective student is to make appropriate decisions regarding the suitability of particular programs. Not only does this task relate to the content and learning outcomes of programs, but also to the range of choices available to many students nowadays regarding mode of study (distance, online, on-campus, flexi-mode); speed of progression (part-time, full-time, flexible progression); and pathways through programs (core and specialist strands, flexible pathways). For those unfamiliar with the landscape of higher education, these are often difficult decisions to make alone. Added to this, is the difficulty of knowing what to ask of whom. To the outsider, universities are labyrinthine places with multiple contact points for different issues.

Most participants in this study adopted an approach of plunging in first and sorting things out later. This was possible because they were enrolled in relatively flexible programs:

Sharon: "When I started university, I felt that I needed the internal experience and I also felt that I'd be more motivated if I was studying internally with the lectures. After a year or so I started to do external units and I was a bit 'not too sure,' not feeling really confident about doing them, but I found external study to be really, really good."

Frank: "The degree, by studying external, was portable. I could take my unit study books away with me on army camps, if I was instructing I had free time and I'd be reading so I could take those things with me even with cubbing. It gave me the flexibility to study when I had spare time."

These are students who have found that distance learning suited their needs, and they were able to succeed in independent learning environments. In Sharon's case, it took some experience and development of confidence before she was able to move into distance education. Because they had little understanding of the implications or their preferences at the point of entry, it is interesting to question what may have become of these students had they not had the flexibility to move between internal and external study within their programs.

Although criticism could be levelled at the lack of depth and quality of information made available to students in the pre-enrolment stage in many universities, it is also important to acknowledge the relatively unformed and multi-dimensional nature of student inquiries at this point. As they embark upon the journey that will begin to test their interest and motivation, they will inevitably have multiple points of enquiry. Three participants in this study cited the importance of thorough research as a precursor to making sound, informed decisions about where and what they would study:

Frank: "Consult widely, that's the advice I would give people. Go the student union, go to the course co-ordinators, speak to them, get as much information as you can about the subject or degree that you want to do."

An associated issue is the ease and approachability of academic and administrative staff. Preenrolment students are clearly vulnerable and may be plagued with fears regarding their ability to 
Bird \& Morgan Adults Contemplating University Study at a Distance: Issues, themes and concerns

succeed. They also may carry with them a stereotype of the academic as the lofty, all-powerful sage. Add to this the difficulty for potential distance learners to make contact by phone during office hours, and we start to get a picture of how straining this task can become, particularly if one's questions are still unformed. Evans (1994, p. 73) comments, "If the student is relatively powerless, then arguably, the potential student is even more so." In comparison to enrolled students, who develop their own networks of information, Evans adds, "Potential students have to rely on personal knowledge, strategies and skills to ensure that they obtain the best information they can and take the best decision on their course as a consequence.”

An important aim of any pre-entry guidance and support offered, is to eliminate the 'chance factor' from prospective students' inquiries, ensuring that, wherever possible, information is sought from the correct sources, appropriate questions are asked, and responses understood. While it is unlikely that all issues can be anticipated and resolved at this time, there will always be a certain degree of 'plunging in' necessary, as reported by the respondents in this study.

For adults contemplating distance education 'getting it right' the first time is particularly important. Distance education learners may be more vulnerable to the effects of an incorrect or inappropriate decision about a program, a mode of study, or even a first unit of study. If things go wrong at the beginning, fears of inadequacy may be exacerbated and, in isolation, the student may choose to quietly discontinue their studies. Again, prospective students need to be alerted to this possibility and provided with information about sources of assistance and guidance in the event of an error. Prospective distance students need to be alerted to the early dangers of self-blame and the internalising of beliefs about failure, and reassured that in many instances a change of unit or mode of study may be all that is required to ensure success.

\section{Theme 6: Identity Change}

In the adult and distance education literature, identity change and self-transformation are most commonly framed as processes that occur during the course of study. Mezirow's (1977; 1981; 1991) theory of 'perspective transformation' is cited often, whereby an individual's assumed and unrecognised cultural and psychological assumptions are challenged, allowing the potential for critical awareness and reappraisal and subsequent changes in values and behaviours.

However, Finnane (1991) and Britton and Baxter (1999) suggest that the process of identity change has, in fact, already begun by the time people decide to apply for university. They argue that, for a variety of reasons, such people have begun to re-conceptualise a 'new self' as part of their decision making process. "Becoming a mature student can therefore be understood as part of the continuous process of identity construction which is seen to be central to modern life," (Giddens, 1991; Beck, 1992; in Britton and Baxter, 1999, p. 180. Similarly, Finnane (1991, p. 158) comments: "The first uncertain thoughts about undertaking study that so many of us can recall, thoughts which led to our making an enquiry to one or other institution, clearly come at a point in our lives that is critical, however dimly we might perceive it, and from that point on it is changed and changing persons who embark upon courses of study.”

The theme of 'identity change' emerged from the data as a theme linked closely too, but separate from, the theme of fears. Issues touched on by participants fell into two distinct categories:

First there were positive identity changes, which acted as motivators towards choosing and remaining committed to study: increasing confidence, learning how to think, learning about one's self, learning about the world. 
Judy: "I thought if I get nothing else out of it, I'm more confident and I can think more broadly."

Phyllis: "One of the difficulties with being a mature aged student is that as you move along, you realise that you had a life . . . and all of a sudden you are doing things to yourself that you just think, 'Oh my goodness, why, oh why, oh why? I could go home and live quite happily. I don't need this.' Yet once you break through that barrier there's a tremendous joy!"

Phyllis: "University has altered me dramatically from being a rather frightened anxious person into. . I I discovered this is where I like to be."

Second, there were challenges to identity with which some participants struggled, persisted with, and 'broke through' in the end: overcoming negative beliefs about being 'dumb/ stupid,' doubts about the decision, disruption and changes to lifestyle.

Phyllis: "There's certain things you've grown up with, that you believe about yourself, that you believe that you're stupid, you believe that you can't learn. You can go on believing that if you so choose or you can do something about it and it's a great revelation to go somewhere along the line. 'Hang on a minute I'm not as thick as I thought I was.'”

Evans (1984, p. 65) ponders a question for prospective or new students: "Do they realize the potentially far-reaching implications of studying?" Another question might well be "Do you realize how much you have already changed to get to this point of even being interested in university study?” Helping prospective mature aged students understand that they are already engaged in a process of change may add extra light to their decision making process, helping them to clarify their goals and motivation for study. As was the case for their fears, all respondents in this study, irrespective of their status as on-campus or distance learners, commented on the impact university study had on their identity. Neither the literature nor this study has explored possible differences for distance education students in the quality and the intensity of identity changes. Further research in this area is required.

\section{Conclusion}

This study has identified issues, themes and concerns arising for pre-enrolment distance students seeking to enter higher education, and has highlighted some reasons why students persist. The key theme, which has overarching implications for all students, is that of motivation. Researchers observed that participants whose motivation and commitment remained high were able to resolve many of their concerns and problems regarding family support, disability, fear of failure, financial issues, and so forth. On the other hand, participants whose motivations were unclear, wavering or inadequate (such as pressure from others rather than one's own intrinsic desire) were more likely to falter when they encountered hurdles of various kinds. As suggested earlier, pre-entry guidance can help learners to unpack and reflect upon their motivations and provide a 'reality check' regarding their needs and what universities can actually offer.

The themes uncovered in this study could inform and provide structure to any pre-entry guidance, support or counselling offered to mature aged distance students. In addition to the issue of motivation, the following issues should be discussed with potential students well prior to their decision to enrol: 
Bird \& Morgan Adults Contemplating University Study at a Distance: Issues, themes and concerns

- $\quad$ Articulating and managing their fears

- Building academic skills through available academic preparation courses

- Building computer and information literacy skills

- Thoroughly researching the degree programs in which prospective students are interested

- Exploring the impact of study on roles within the family and strategies for preparing for changes

- Considering the impact of study on work and financial commitments, and strategies for preparing for changes

- Anticipating the impact of study on self and identity

- Identifying support networks relevant to the needs of the student

In offering guidance to prospective distance students, all sources of potential support need to be discussed. In many instances, it will be the informal family and student networks that will be of most value to students studying at a distance.

Equally important will be the range of academic and student support services available to distance education students at the particular university, and within particular schools or faculties, in which they are enrolling. Many universities now offer easily accessible student administration and support services via the university website. For example, one university offers an ongoing online stress management discussion forum for distance learners. Acting as regional liaison officers for distance learners, another has identified individuals in every region throughout the state. Universities, and schools or faculties within universities, will have different levels of support for distance learners depending on the duration and breadth of their experience with distance education provision. Academic support from within schools and faculties take various forms and may include the provision of online interactive learning environments, teleconferencing, email, student contact lists, residential stays, travelling workshops, and so on.

The primary goal of guidance and counselling for prospective distance students is to assist them in making an informed decision as to whether to attend university or not. Successful outcomes are more likely when students are able to make a decision based on sound information. Another goal is to identify and discuss with prospective distance students common emotional responses to returning to study at university, and common pitfalls in distance education: fear, isolation, lack of support, and so on.

Intervention at this early stage can be viewed as an investment that may well contribute to improved retention rates, although this connection requires further research.

\section{References}

Bourke, S., Cantwell, R., and Archer, J. (1998). Evaluation of an Equity Program for University Entrance. HERDSA Conference proceedings, Auckland, 7-10 July. 
Britton, C., and Baxter A. (1999). Becoming a Mature Student: Gendered narratives of the self. Gender and Education 11(2), pp. 179 - 193.

Brown, K. (1996). The role of internal and external factors in the discontinuation of off-campus. Distance Education 17(1), 44 - 7.

Calder, J., and McCallum, A. (1998). Open and Flexible Learning in Vocational Education and Training. London: Kogan Page.

Candy, P. C. (1991). Self-direction for lifelong learning. SanFrancisco: Jossey Bass.

Cantwell, R., and Mulhearn, W. (1997). The adjustment behaviours of mature-aged women returning to formal study. Paper presented at the 1997 AARE Conference, Brisbane. Retrieved March 31, 2003 from: http://ww.aare.edu.au/97pap/cantr050.htm

Evans, T. (1994). Understanding Open and Distance Learners. London: Kogan Page.

Finnane, P. (1991). Personal and Professional Worlds of the Student: Distance Teaching and Learning. Geelong: University of South Australia and Deakin University.

Garland, M. (1993). Student perceptions of the situational, insitutional, dispositional and epistemological barriers to persistence. Distance Education 14(2), 181 - 198.

Gibbs, G., Morgan, A. R., and Taylor, E. (1984). The world of the learner. In F. Marton, N. Enwistle, and D. Hounsell (Eds.) The Experience of Learning. Edinburgh: Scottish Academic Press.

Glaser, B., and Strauss, A. (1967). The discovery of grounded theory. Chicago, IL.: Aldine.

Grace, L. J., and Smith, P. J. (2001). Flexible Delivery in the Australian Vocational Education and Training Sector: Barriers to success identified in case studies of four adult learners. Distance Education 22(2), 196 - 211.

Inglis, A. (1996). Teaching-learning specialists' conceptions of their role in the design of distance learning packages. Distance Education 17(2), 267 - 288.

Lincoln, Y., and Guba, E. (1985). Naturalistic Inquiry. Hollywood, CA.: Sage.

Marton ,F. (1986). Phenomenography: A research approach to investigating different understandings of reality. Journal of Thought 21(3), $28-49$.

Marton, F., Housell, D. and Entwistle, N. (1997). The Experience of Learning Implications for Teaching and Studying in Higher Education 2nd edition. Edinburgh: Scottish Academic Press.

Mezirow, J. (1977). Perspective transformation. Studies in adult education, 9(2), 153 - 164.

Mezirow, J. (1981). A critical theory of adult learning and education. Adult Education, 32(1), 3 24. 
Mezirow, J. (1991). Transformative dimensions of adult learning. San Fransisco: Jossey-Bass.

Morgan, C., Dingsdag, D., and Saenger, H. (1998). Learning Strategies for Distance Learners: Do they work? Distance Education 19(1). 142 - 156.

Morgan, C., and O’Reilly, M. (1999). Assessing Open and Distance Learners. London: Kogan Page.

Parr, E. (1996). Dropping in and Dropping Out: An alternative view of attrition Lismore. Southern Cross University

Polkinghorne, D. E. (1991). Generalization and qualitative research: issues of external validity. Paper presented at the annual meeting of the AERA, Chicago, April 21 - 25.

Thorpe, M. (1987). Adult learners in open learning. In M. Thorpe and D. Grugeon (Eds.) Open Learning for Adults. Essex, UK: Longman Harlow. 71 - 82.

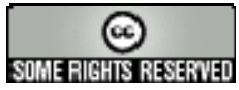

